\title{
La ciencia al servicio del arte. Entrevista a Araceli Gabaldón, físico del Instituto del Patrimonio Cultural de España
}

\author{
Por Rocío Bruquetas Galán y Marisa Gómez González
}

\begin{abstract}
Araceli Gabaldón, física del Instituto del Patrimonio Cultural de España, ba dedicado su larga vida profesional a los estudios físicos aplicados a la conservación de los bienes culturales. Conocedoras de la importancia de su trabajo, hemos querido dedicarle esta breve entrevista en Ge-conservación/conservação, resumen de una agradable conversación que compartimos con ella este verano.
\end{abstract}

\section{Breve reseña de Araceli Gabaldón:}

39 años trabajando en la administración de Cultura y, de ellos, 30 en el Laboratorio de Estudios Físicos del Instituto del Patrimonio Cultural de España (Ministerio de Cultura), Araceli Gabaldón es una figura clave en España para el desarrollo de la radiografía y la reflectografía aplicadas al estudio de los bienes culturales. Ella y Tomás Antelo, con quien ha formado un tándem inseparable en el IPCE todos estos años, han dedicado gran parte de su vida profesional a investigar, adaptar y aplicar soluciones tecnológicas de otros sectores, como la industria o la medicina, al campo del patrimonio cultural, mucho más minoritario y menos apoyado económicamente en lo que se refiere a investigación. En esta línea sus logros son notables. Uno de ellos es el Proyecto VARIN, un gran avance que ha permitido intervenir sobre grandes formatos sin necesidad de desmontar, como hicieron con sus estudios radiográficos y reflectográficos de los retablos de Santa María de Trujillo, de Santo Domingo de la Calzada, de Carbonero el Mayor. La oportunidad de estudiar conjuntamente un número amplio de obras de un mismo artista o taller les ha llevado a orientar también sus

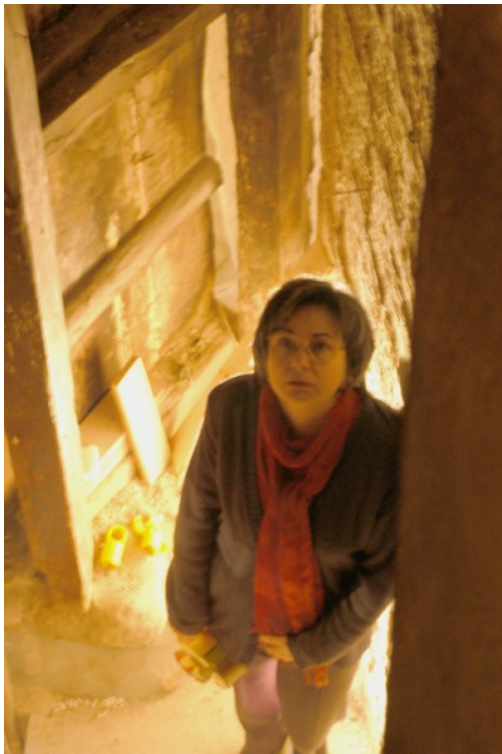

Detrás del retablo de la Iglesia de Santa María de Trujillo, Cáceres. Foto CTomás Antelo. investigaciones hacia estudios técnicos de gran interés para la conservación y la historia del arte. Un ejemplo es el proyecto de Fernando Gallego, en el que, junto con Carmen Vega, han estudiado las radiografías y reflectografías de más cien obras atribuidas a este pintor castellano y en el que siguen trabajando en la actualidad. Fruto de todo este trabajo son sus publicaciones en libros y revistas especializadas, así como los cursos y conferencias que ha impartido sobre los resultados de sus trabajos y metodologías.

En efecto, la aplicación de estas técnicas a las obras restauradas por el IPCE durante más de 25 años les ha permitido desarrollar una metodología de interpretación de los documentos basada en un profundo conocimiento de las técnicas físicas, de las imágenes resultantes y, sobre todo, de ese "saber ver" que les ha proporcionado su larga experiencia ante las obras. Conscientes del valor de los fondos radiográficos que guardan y de su potencial como fuente de investigación y documentación, ambos pusieron en marcha un proyecto del que Araceli se siente particularmente orgullosa, el archivo de radiografías del IPCE, llamado en honor a sus iniciadores "Archivo Gabaldón-Antelo". Este archivo guarda un considerable número de radiografías de pinturas, 
esculturas, objetos arqueológicos y etnográficos, artes decorativas y textiles, correspondientes a los casi 50 años de existencia del Instituto y que en la actualidad, gracias a su empeño, se está digitalizando y catalogando.

Pero como compañeras suyas queremos destacar además la naturaleza personal de Araceli, su admirable tesón y eficiencia, su generosidad y su entusiasmo, sin los que no habría sido posible construir y fortalecer el actual Laboratorio de Estudios Físicos del IPCE. Tanto Tomás como ella han sido la génesis y el motor de este departamento, que hoy día constituye una referencia imprescindible en el mundo de la conservación científica española. Hace falta ahora la revisión panorámica de toda una labor, no solo por el merecido reconocimiento a sus años de trabajo, sino por la necesidad de situar en su plena dimensión el aporte profesional que nos lega.

Araceli Gabaldón estudió Físicas en la Universidad Complutense de Madrid en los años 60. La primera parte de su vida profesional la dedicó a la enseñanza media. Después de unos años en el Archivo Fotográfico de Arqueología del Ministerio de Cultura, pasará a formar parte de la plantilla del Instituto Central de Restauración y Conservación de Obras de Arte, Arqueología y Etnología, el antiguo ICROA.

\section{Entrevista:}

Rocío y Marisa. Araceli: ¿qué fue lo que te llevó a interesarte por el patrimonio cultural, lo que te acercó a este mundo?

Araceli Gabaldón. Fue la casualidad. Yo estaba en el Archivo Fotográfico de Arqueología y necesitaban una persona con formación de ciencias para la instalación radioactiva del Instituto Central de Restauración de Obras de Arte y Arqueología (ICROA), y yo era de las pocas personas en el Ministerio de Cultura que la tenía pero no estaba ejerciendo funciones de acuerdo con su especialidad. El que era entonces director del ICROA, D. Ignacio Gárate, y mi compañera Montse Algeró, pensaron en mí. Yo provenía de la enseñanza media y este ofrecimiento suponía un cambio radical en mi anterior profesión, un reto que me interesó afrontar.

R. y M. Tú has conocido las distintas etapas de la trayectoria del Instituto del Patrimonio Cultural de España, desde el primer ICROA al actual IPCE. Desde tu experiencia ¿qué destacarías de cada una de ellas?

A.G. El Instituto que yo conocí, el ICROA, lo calificaría de un instituto familiar, con poco presupuesto y medios, pero con profesionales de alta cualificación en continuo contacto entre sí. Se ocupaba de un campo del patrimonio más pequeño que ahora, las obras de arte y arqueología. El de ahora está muy bien dotado, tanto de medios como de personal, aunque siempre es mejorable. Fue Ignacio Garate quien, con su visión de futuro, hizo el primer intento por dotar al instituto que él dirigía de nuevo personal técnico, consiguiendo el traslado desde otras direcciones del Ministerio de cuantas personas pudo, además de iniciar la convocatoria de nuevas plazas para ampliar el laboratorio, que fue cuando se incorporaron Juan Antonio Herraez, Marisa Gómez o Miguel Ángel Rodriguez. También inició conversaciones con la Universidad Complutense para conseguir nuestro actual edificio. Pero fue Jaime Brihuega el que consiguió llevar a término esta labor. Su ilusión por este proyecto fue tanta que, unida a la nuestra, logró dar al ICROA el gran empujón que le permitió convertirse en lo que es en la actualidad. Él promovió la unificación que se produjo con el ICRBC, reuniendo en un solo centro departamentos dispersos relacionados con la conservación que dieron lugar al Instituto actual. Fue, en mi opinión, algo muy importante porque permitió relacionarse entre sí a las personas que trabajaban en ellos y que pudieran ampliar su espectro de conocimientos. La comunicación es mucho más fluida cuando hay una cercanía física, sin duda, y eso posibilita abordar los estudios de forma más completa como requieren los bienes culturales. 
R. y M. ¿Cómo fue tu primer contacto con el mundo de los estudios físicos de las obras de arte y cómo te formaste en este campo?

A.G. Tomás y yo hemos sido demasiado autodidactas. Llegué desorientada a un campo totalmente nuevo para mí y me he sentido muy apoyada, en lo que se refiere a nuestro arranque radiográfico, por otros profesionales de centros como el INTA (Instituto Nacional de Técnica Aeroespacial) con Gabriel Delojo y el CENIM (Centro de Investigaciones Metalúrgicas), con Antonio Martín, Víctor López y Eduardo Otero. También lo fuimos por los jefes de servicio de protección radiológica de distintos hospitales, como Pilar Lopez Franco, Leopoldo Herrez, Pilar

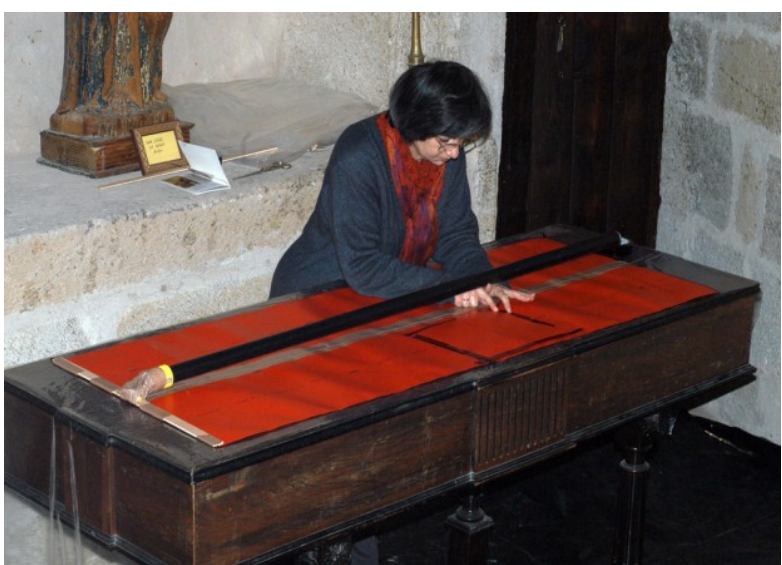

Montando las placas radiográficas en el retablo de la Iglesia de Santa María de Trujillo, Cáceres. Foto CTomás Antelo. Olivares etc, o por el Servicio de Dosimetría del Ministerio de Sanidad y Consumo, con Mercedes Bezares. Pero sobre todo hemos sido sobre todo autodidactas. Uno de los mayores avances que tuvimos fue la incorporación al equipo de una restauradora del Instituto, María Yravedra. Ella era muy exigente en la selección de obras, pero nos estimuló mucho porque nos obligaba a hacer cosas que luego siempre resultaban interesantes. Fue muy importante en nuestra trayectoria.

R. y M. Esa es una carencia que todavía existe, la de la formación especializada en conservación científica.

A.G. Sí, una de las cosas que echo en falta en el Instituto actual es nuestra formación. Pensamos que hay que facilitar el contacto con otras instituciones y profesionales, nosotros impartimos muchos cursos, pero creo que todo profesional debe ampliar continuamente su formación, asintiendo también a cursos o estancias en otras instituciones.

R. y M. Pero de la comunicación con otros profesionales de la conservación y restauración nos hemos ido nutriendo unos y otros, es una de las bases de nuestra formación ¿¿ué ha supuesto para ti la oportunidad de relacionarte con ellos todos estos años?

A.G. Enriquecerme con el intercambio y ampliar mi visión, analizar las cosas desde otro punto de vista. Al final nos convertimos en unos híbridos. Mi evolución personal ha sido muy grande gracias al contacto con otros profesionales que te abren los ojos a un mundo nuevo, ver las obras de arte desde su punto de vista, que poco a poco va siendo también la tuya y viceversa ... Te ayuda a dar importancia a cosas que yo sola no hubiera detectado, adquieres otra sensibilidad. Por ejemplo, si yo no hubiera trabajado en esto no me hubiera dado pena que tiraran el ayuntamiento de mi pueblo para construir otro nuevo como están haciendo, valoras otras cosas. Eso es lo que me han transmitido muchas personas con las que he trabajado.

R. y M. Desde nuestro ámbito de la conservación y restauración no hay mucho acuerdo en el empleo de los términos que definen nuestras distintas especialidades, por ejemplo, "conservador", "restaurador", "conservador-restaurador", "conservador del patrimonio" ... En el ejercicio de tu profesión ¿cómo te definirías: "conservadora científica", "científica de la conservación"...?

A.G. Como conservadora a secas. Todos los que estamos en este mundo somos conservadores. Nos acercamos a la conservación del patrimonio de manera diferente. El nombre de científico se da a los que venimos de ciencias experimentales, pero también es científico un historiador, un 
arqueólogo ... Todos desde nuestras distintas especialidades somos conservadores del patrimonio cultural. El cuerpo de conservadores de museos debería ampliarse a las otras ramas o actividades profesionales -restauradores, físicos, biólogos, químicos, etnólogos ...- que trabajan desde distintos ámbitos pero en la misma dirección, proteger y conservar el patrimonio. También la amplitud que hoy tiene el concepto de patrimonio pide esta integración y actualización.

R. y M. Tu trabajo lo aplicas a la conservación y restauración y al estudio técnico-histórico de las obras. ¿En qué medida te sientes identificada con cada una de estas áreas y qué prioridad les darías?

A.G. Nosotros lo que hacemos es una forma de conocer mejor la obra, y eso ayuda a su conservación y restauración, pero también ayuda a la historia del arte. Las radiografías, reflectografías y otro tipo de imágenes con técnicas físicas nos proporcionan un documento irrepetible, en sí mismo valioso, que ofrece información, muchas veces no visible, sobre el estado material de la obra en un momento determinado. Son un apoyo a la restauración y también a los historiadores del arte o los arqueólogos. ¿Qué es más importante? Depende de las prioridades de cada momento. No es fácil trazar la línea, es un círculo. Los estudios físicos nos pueden ayudar a acercar las obras a determinados autores, escuelas o fechas.

R. y M. En efecto, para fijar unos criterios adecuados de conservación y restauración es imprescindible conocer la obra en todas sus dimensiones: la material, la formal y la simbólica. No se pueden separar. Y lo mismo, desde la conservación se aportan datos necesarios para una mejor interpretación histórica de las obras.

R. y M. ¿Cuál es la parte que crees más interesante de tu trabajo? ¿La puesta a punto de nuevos métodos de aplicación de los ensayos físicos? ¿La aplicación en si misma a las obras? ¿La interpretación de los resultados?

A.G. Para mí la parte más interesante es intentar adaptar los avances de otros campos al nuestro, teniendo en cuenta que el dinero del que se dispone en el patrimonio cultural no es comparable con el de la industria o la medicina, siempre mucho mejor dotados, tenemos que acudir a otros grandes sectores de la radiografía. En esto hemos trabajado mucho Tomás y yo, en adaptar tecnologías de otros campos a nuestras necesidades. Un ejemplo es el proyecto VARIM. Los sistemas más apropiados para la captación de las imágenes infrarrojas se caracterizan por su baja resolución espacial, son imágenes con pocos pixel, lo que obliga a ir captando pequeñas áreas de la imagen que luego se ensamblan. Por este motivo J. Cupitt y su equipo desarrollaron el magnífico software VIPS, aunque inicialmente se concibió en un entorno UNIX, en el que habitualmente la administración española no trabaja, y la unión se hacía imagen por imagen. Eso nos llevo a iniciar el Proyecto VARIM, que trabajaría en el entorno Windows, y cuyo software sería gratuito tanto para los profesionales de las administraciones públicas como para estudiantes. Pensábamos especialmente en los doctorandos, que habitualmente tienen muy pocas ayudas. Pero nuestra meta fue más ambiciosa, conseguir mecanizar el sistema, captar y unir las imágenes automáticamente. Por supuesto la unión, siempre y cuando la obra se dejara, de todos es conocido el alabeo que presentan algunas tablas. El sistema ha funcionado muy bien durante estos años pero en este momento exige una modernización, nuevo reto para el laboratorio, que apoyado por la jefe de área se está a punto de conseguir.

Otro ejemplo es el modelo industrial de película continua en rollo -por cierto, fue D. Esteban Llagosteres, autor de un magnifico estudio radiográfico sobre momias, el primero que nos hizo ver la importancia de la película radiográfica en rollo para nuestro trabajo- cuyos distintos anchos y longitudes de hasta 60 metros nos han permitido radiografiar sin necesidad de desmontar retablos.

R. y M. También habéis aplicado el sistema a pinturas sobre lienzos de gran formato, como el "Guernica" de Picasso. 
A.G. Sí, y ha sido la pintura sobre lienzo que nos ha planteado más dificultades para su captación: conseguir hacerlo todo de una vez, la baja absorción radiográfica de sus materiales y las dificultades de su manipulación. Pero al final, gracias como siempre al ingenio de Tomas y al equipo que formamos con nuestros colegas del Reina Sofía, conseguimos un documento del que todos nos sentimos orgullosos.

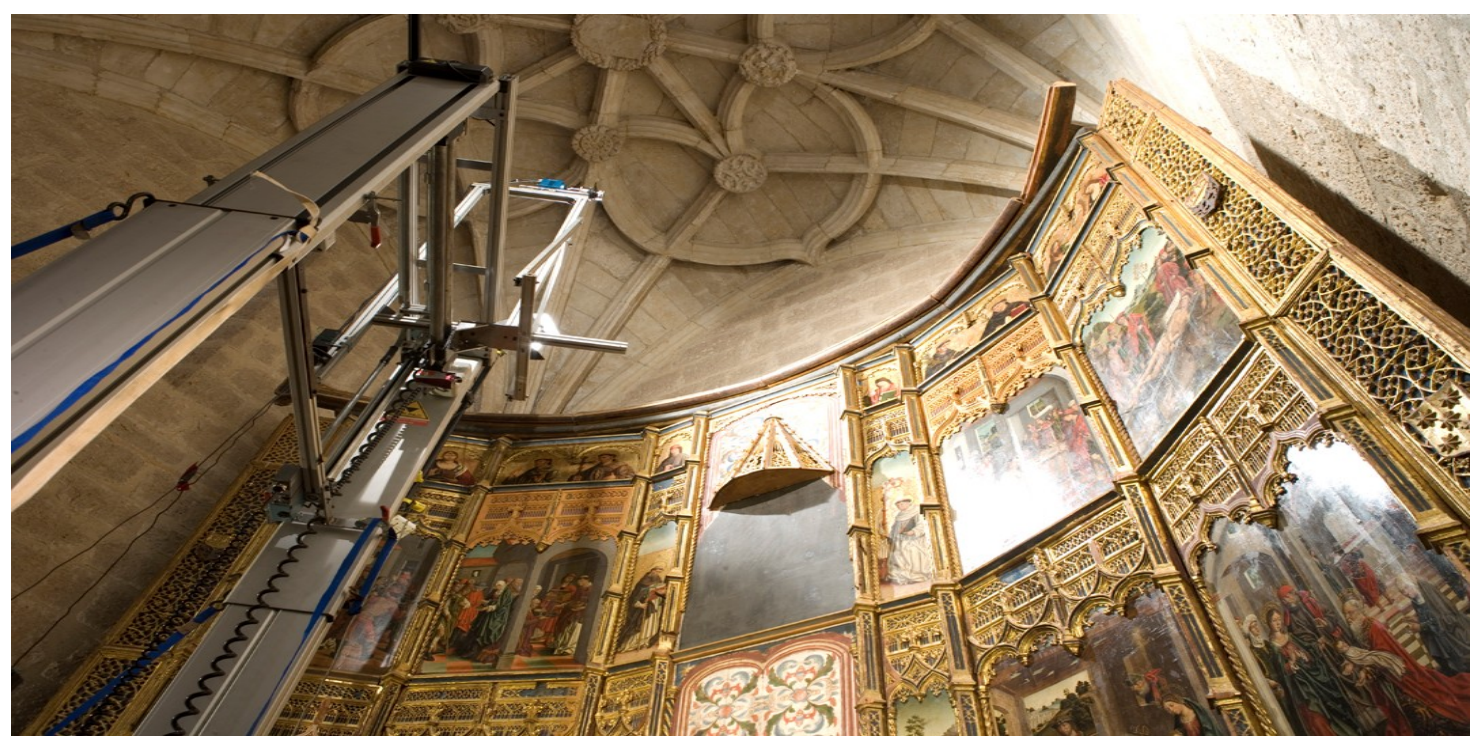

Detalle del estudio reflectográfo en la Iglesia de San Lorenzo de Toro, Zamora. Foto CTomás Antelo.

R. y M. De todos los proyectos que has abordado ¿Cuál es el que más satisfacciones te ha dado? ¿El proyecto VARIM, la organización del archivo radiográfico, la digitalización y la creación de una base de datos de las imágenes, el estudio de Fernando Gallego...?

A.G. Todos, pero el más beneficioso por su mayor proyección en el entorno ha sido el archivo radiográfico y el inicio del proyecto OMAR de su digitalización y catalogación. Con la incorporación de Ángeles Anaya y Miriam Bueso se inició el camino y, por supuesto, con el apoyo de la Jefe de Área, Marián del Egido, y de todo el servicio económico, encabezado por su jefe José Algora. También gracias a la dirección actual el Instituto está bien dotado, con posibilidades de ir mejorando su infraestructura.

R. y M. Lleváis varios años estudiando un amplio conjunto de obras de Fernando Gallego. ¿Qué no puedes decir sobre este proyecto y sobre vuestra metodología de estudio?

A.G. El archivo del IPHE contaba ya con una serie de radiografías y reflectografías de obras atribuidas a Fernando Gallego que nos permitía un estudio comparativo, por lo que pensamos integrar los resultados en un proyecto más amplio de la pintura sobre tablas de los siglos XV y XVI. Hemos intentado orientar este tipo de análisis a la obtención de una documentación de calidad. En interpretación no nos considerábamos capacitados y nos centramos en conseguir una documentación de calidad empujados por las exigencias de nuestros compañeros para los que iban destinados los documentos, que a su vez nos enseñaban a buscar cosas en ellos, pero también nosotros hemos buscado otras. Por ejemplo, en radiografía hemos empezado a desarrollar una metodología de interpretación basada no tanto en los aspectos estilísticos, más propios de los historiadores del arte, sino en otra forma de ver la radiografía. Con la interpretación de la radiografía de pintura, nosotros nos preguntábamos ¿podemos saber algo más desde otro punto de vista que no sea el histórico, basado fundamentalmente en los aspectos estilísticos? En este 
momento está en vías de desarrollo una metodología de interpretación que pensamos se acercara más a la experimental. El tiempo nos dirá si efectivamente nuestras hipótesis son acertadas y la metodología resulta válida.

Araceli y Tomás siempre han sido muy rigurosos en la interpretación, la hacen desde la imagen que resulta de la respuesta de la materia a los rayos X, algo que no siempre se sabe hacer correctamente. Hay que "saber ver" y para eso bacen falta horas y horas delante de una radiografía. Si se sistematizara esa metodología podría ser un instrumento fundamental para la lectura del documento radiográfico, una guia para los que empiezan a trabajar en este campo.

R. y M. ¿Qué acontecimientos o qué logros destacarías en la evolución de los estudios físicos en los últimos años?

A.G. A lo largo de estos años se ha conseguido que se reconozca su importancia como herramienta para el estudio de los bienes culturales. El problema es que son análisis muy costosos y es una pena que no se puedan aplicar siempre. Lo ideal sería establecer protocolos de actuación que faciliten una sistemática en el trabajo, que permitan aplicar los análisis necesarios en cada caso. Y por supuesto formar especialistas en este campo, entre las nuevas generaciones.
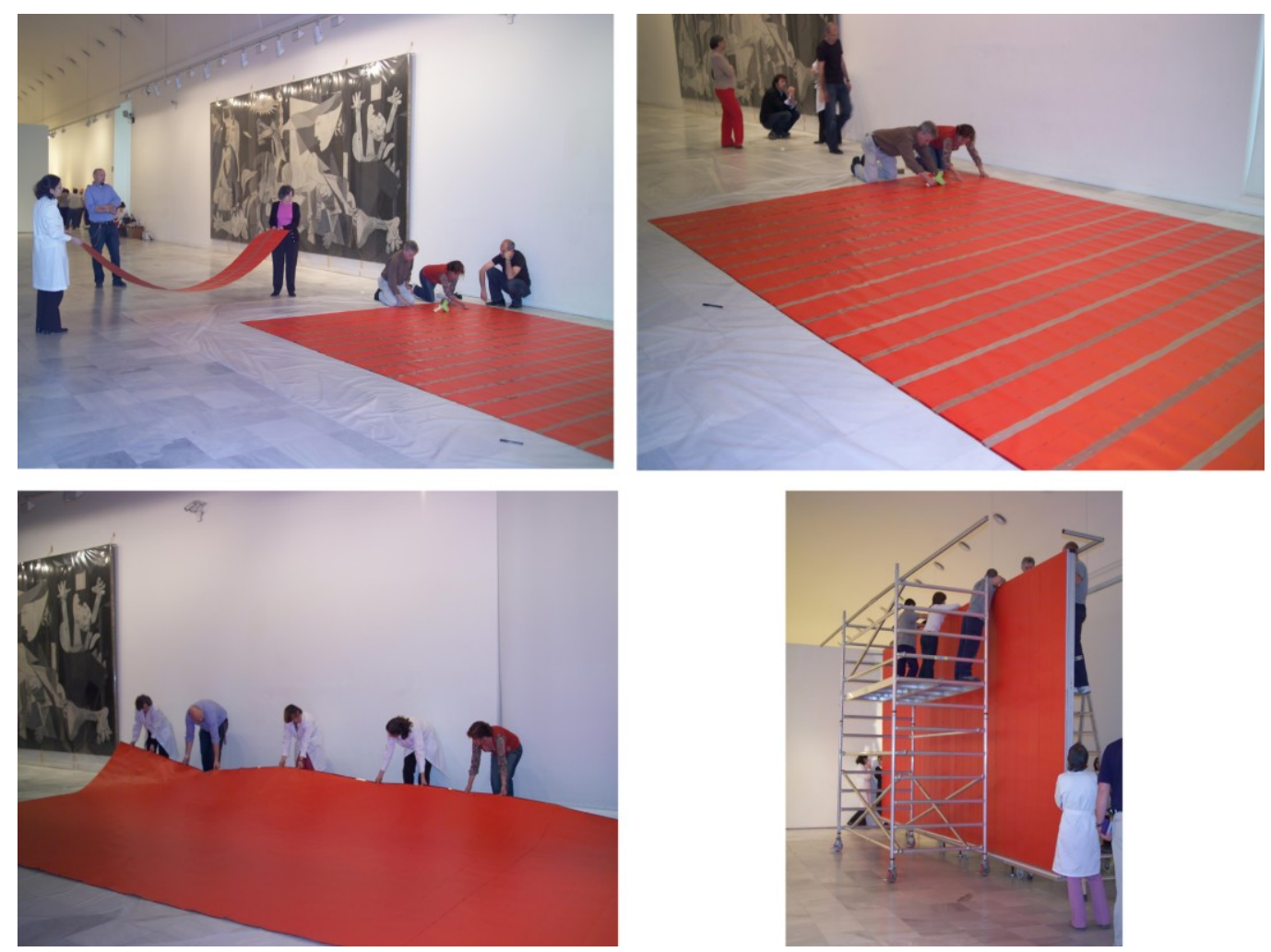

Montaje de la radiografía del Guernica en el MNCARS. Foto CTomás Antelo.

R. y M. A partir de tu experiencia y con vistas al futuro ¿qué funciones crees que debería acometer un Centro como el IPCE en una España administrativamente descentralizada?

A.G. Dado que el IPCE es el primer instituto que cuenta con personal una amplia experiencia profesional, deberíamos ser un nexo de unión entre los diferentes institutos, podría ser un centro de referencia por las investigaciones que aquí se realicen para otros centros que no tienen tantos especialistas, porque tenemos la suerte de poder dedicarnos a áreas muy concretas, somos 
afortunados y por eso deberíamos desarrollar más esa especialización, que es nuestro fuerte, porque no en todos los sitios se puede.

R. y M. Crees que hay un paralelismo entre la situación de España y el mundo occidental?

A.G. En este momento España ha evolucionado mucho y en general estamos al mismo nivel que otros países de nuestro entorno. Cuando se creó el ICCROM, España estaba a años luz del resto de Europa, ahora estamos al mismo nivel, mejor en unas cosas, peor en otras ... Pecamos siempre de baja autoestima, por supuesto que debemos aprender de lo que se hace en otros países, pero nosotros también podemos aportar mucho, podemos hablarnos de tu a tu ...

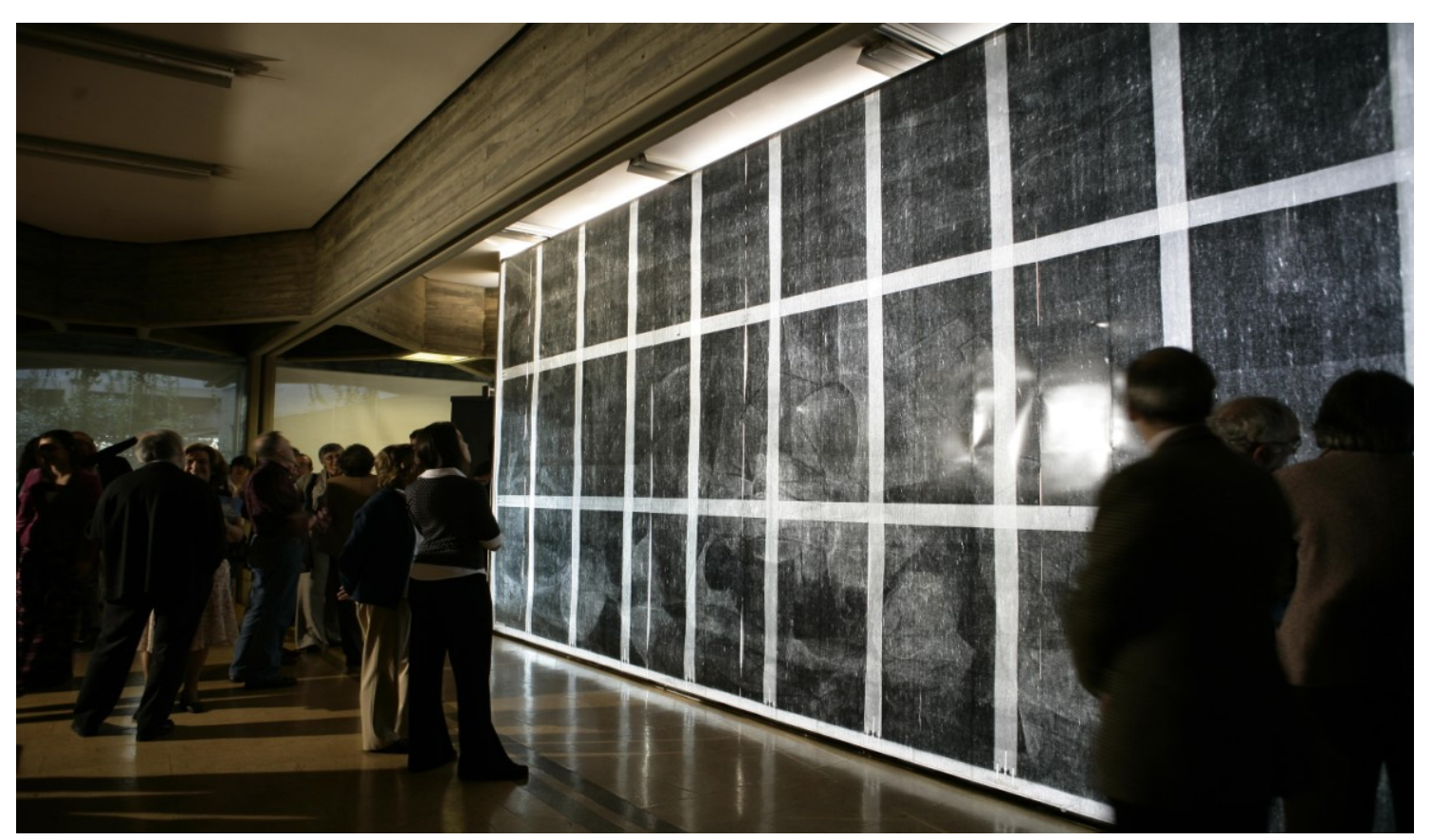

La radiografía del Guernica expuesta en el IPCE. Foto CTomás Antelo.

Ante la pregunta sobre el papel que juegan la investigación cientifica, histórica y metodológica en la conservación del Patrimonio Cultural, Araceli no ve necesario dar más explicaciones y contesta concisa: fundamental e imprescindible en el momento actual. Pero en la signiente acertamos en un tema que para ella ha sido especialmente gratificante:

R. y M. En tus viajes de trabajo para realizar estudios "in situ" has tenido experiencias muy variadas y seguramente enriquecedoras con la población local. ¿Ves necesaria la difusión social del patrimonio y su conservación, y de los estudios físicos de bienes culturales en particular?

A.G. Nuestra experiencia personal en esto ha sido de lo más enriquecedora, siempre hemos encontrado un apoyo por parte de párrocos, alcaldes y personas encargadas de las obras que íbamos a estudiar, cada vez que lo recuerdo me llena de satisfacción. Cuando había que mover un equipo nos ayudaba desde el alcalde al párroco, hasta el vecino que pasaba por la calle. Hay que tener en cuenta que Tomás y yo estábamos solos muchas veces.

Pero por otro lado hemos carecido de algo muy importante, de hacer llegar nuestros estudios a la comunidad local donde hemos ido a trabajar. Ese es un reto que le lanzo al IPCE, deberían hacerse pequeñas exposiciones locales para hacer llegar el trabajo que realizamos a todos los niveles de la población porque de esa manera conocerían una faceta de su patrimonio. No creo que eso ayude a valorarlo más, porque mi experiencia me ha hecho ver que suelen tener verdadero cariño por sus 
obras de arte, pero sí ampliaría sus conocimientos. Por otro lado, sería un aliciente turístico más, fomentaría un turismo cultural del que estamos tan necesitados y, por ende, otra forma de dar a conocer el trabajo del IPCE.

R. y M. La sociedad tiene la responsabilidad de la transmisión del Patrimonio Cultural a las futuras generaciones, aunque también puede ser su principal depredador ¿Qué piensas sobre el papel que debería cumplir la sociedad en la conservación y uso del Patrimonio?

A.G.; Lo primero que tiene que hacer la sociedad es educar a los jóvenes a respetar el patrimonio e imbuirles de su historia y de que hemos llegado donde estamos por los antecedentes históricos. Las obras son testimonio del patrimonio cultural en general, tanto material como inmaterial, que nos habla de nuestra evolución. Un país debe conocer su historia para no caer en los errores del pasado. El patrimonio es algo que nos une, es de todos, nos hace sentirnos orgullosos.

R. y M. ¿Qué piensas sobre el futuro de la conservación y restauración en España?

A.G.; El patrimonio no se mantiene del aire, necesita sustentarse en dotación económica suficiente y en suficiente número de profesionales que estén bien preparados. En nuestro campo no hay dónde formarse, y nosotros no estamos transmitiendo nuestros conocimientos y experiencia. El IPCE debería tomar medidas sobre esto, deberíamos formar a otros que puedan continuar con nuestro trabajo y no tengan que partir de cero como nos pasó a nosotros, y como sucederá si no se ataja pronto.

R. y M. Araceli, tú has sido siempre una permanente colaboradora del Grupo Español del I.I.C. ¿Qué opinión te merece esta organización?

A.G. Me merece todo el respecto, creo que están haciendo una maravillosa labor, y no lo digo porque esta sea su revista, sino porque lo he vivido. Son un grupo de personas que luchan por la conservación de nuestro patrimonio desde el otro lado de las instituciones. Su función en la sociedad es fundamental.

R. y M. Gracias, Araceli, y esperamos seguir contando contigo para muchas otras cosas.

A.G.; Gracias a vosotras. También quiero aprovechar para agradecer a y mis compañeros del IPCE, entre ellos muy especialmente Tomás Antelo, y a muchas otras personas por lo que me han ayudado y enseñado en estos 30 años.

\section{Biblografía}

ANTELO, T. y GABALDÓN, A. (1988). "Estudio radiográfico" en Zurbarán. Estudio y Conservación de los monjes de la Cartuja de Jerez, Madrid.

GABALDÓN, A. (1992). "Estudio radiográfico" en El retablo de San Eutropio del Espinar, Madrid.

ANTELO, T. y GABALDÓN, A. (1992). "Estudio radiográfico" en Nuestra Señora de África, proceso de restauración, Madrid.

ANTELO, T.; GABALDÓN, A. y YRAVEDRA, M. (1994). "Comentarios a la imagen radiográfica del Crucificado de la Buena Muerte de la catedral de Madrid" en Madrid en el contexto de lo bispánico desde la época de los descubrimientos, Madrid.

ANTELO, T. y GABALDÓN, A. (1995). "Sistemas de representación de filigranas utilizados en los laboratorios del ICRBC" en Historia del papel en España y sus filigranas (I Congreso Nacional), Investigación y técnica del papel $\mathrm{n}^{\circ} 124$. 
ANTELO, T., GABALDÓN, A. et alii (1996). El tercer bronce botorrita, Gobierno de Aragón.

ANTELO, T., GABALDÓN, A, y YRAVEDRA, M. (1999). "Estudio radiográfico" en Goya en la Fundación Lázaro Galdiano, Madrid.

GABALDÓN, A. (1999). "Técnicas de análisis físico: radiografía y reflectografía de infrarrojos. Aplicaciones al estudio de los bienes culturales" en Ciencia, pensamiento y cultura, Madrid.

ANTELO, T., BRUQUETAS, R. y GABALDÓN, A. (2001). "Dibujo subyacente de la pintura del retablo" en El retablo mayor de la Catedral de Tudela: historia y conservación, Pamplona.

GABALDÓN, A. Clases impartidas en el Curso de datación, autentificación y análisis para el patrimonio históricoartístico, UAM, Madrid. 2002, 2003 y 2005.

ANTELO, T., GABALDÓN, A. y VEGA, C. (2003). "Documentación reflectográfica de la obra de Pedro de Berruguete", Actas del Simposium Internacional Pedro Berruguete y su entorno, Palencia.

ANTElO, T y GABALDÓN, A. (2003). “A propósito del dibujo" en Retablo de Carbonero el Mayor: Restauración e Investigación. Madrid.

ANTELO, T., GABALDÓN, A. et alii (2003). "Estudio radiográfico de una escultura de aleación de base cobre que representa al Doríforo de Policleto", X Congreso binacional de END, Cartagena.

ANTELO, T. y GABALDÓN, A. (2003). "La radiografia de la Piedad del Museo Thyssen Bornemiza y el Entierro de Cristo del Museo de Bellas Artes de Asturias. Análisis comparativo” en Ribera. La Piedad, Madrid.

MARTÍN COSTEA, A., LÓPEZ SERRANO, V. y GABALDÓN GARCÍA, A. (2003). "El conjunto minero-metalúrgico del término municipal de Seno (Bajo Aragón): un ejemplo del origen y difusión de la siderurgia protohistórica en el levante español", Salduie n ${ }^{\circ} 3$.

ANTElO, T., GABALDÓN, A. y VEGA, C. (2004). "Proyecto VARIM (Visión Artificial aplicada a la Reflectografía de Infrarrojos) y sus aplicaciones", Tecnologia y Qalidade no 50, Oporto.

GABALDÓN, A. (2005). "Estudio de obras con reflectógrafo IR" Curso teórico-práctico de tasación, peritaje y expertización de obras de arte. Universidad de León. Noviembre.

ANTELO, T., GABALDÓN, A. y VEGA, C. (2005). "Técnica radiográfica aplicada al estudio de la pintura contemporánea”, VI Reunión del Grupo de Arte Contemporáneo del GEIIC, Madrid.

ANTELO, T., GABALDÓN, A. y VEGA, C. (2005). "El procedimiento radiográfico como técnica de estudio de los metales históricos", $2^{\circ}$ Congresso latino-americano de restauraçao de metais, MAST, Rio de Janeiro.

LÓPEZ, V., OTERO, E., MARTÍN COSTEA, A. y GABALDÓN, A. (2005). "Estudio metalúrgico de un casco griego", $2^{\circ}$ Congresso latino-americano de restauraçao de metais, MAST, Rio de Janeiro.

ANTELO, T., GABALDÓN, A., MARTÍN COSTEA, A. et VEGA, C. (2005). “Aspectos constructivos de algunos torques españoles determinados mediante análisis radiográfico" en Minería y metalurgia históricas en el sudoeste europeo, Madrid.

MARTÍN COSTEA, A., LÓPEZ SERRANO, V. y GABALDÓN GARCÍA, A. (2005). "Sobre el origen y difusión de la siderurgia protohistórica en el Levante español: el conjunto minero-metalúrgico del término municipal de Seno (Bajo Aragón), Revista de metalurgia (CENIM-CSIC), volumen extraordinario. 
ANTELO, T., GABALDÓN, A. y VEGA, C. (2006). "La información obtenida por métodos radiográficos en el estudio de metales", texto del curso cobre Patrimonio metálico, tecnología y conservación. Universidad de Alcalá de Henares. 2006.

ANTElO, T., DEL EGIDO, M., GABALDÓN, A., VEGA, C. y TORRES, J. (2006). "El proyecto VARIM: Visión Artificial aplicada a la Reflectografía de Infrarrojos Mecanizada", Innovación tecnológica en conservación y restauración del Patrimonio. Tecnología y Conservación del Patrimonio Arqueológico I.

GABALDÓN, A; LÓPEZ, V; MARTÍN-COSTEA, A et OTERO, E “Caracterización metalúrgica de tres piezas arqueológicas de materiales base cobre procedentes del Bajo Aragón” en Revista Metalurgia 42 (4), 2006.

GABALDÓN, A. (2006). "Líneas de investigación en el Departamento de Estudios Físicos del IPHE en 2006” en Arbor. Ciencia, pensamiento, cultura, vol CLXXXII, n 717, Madrid.

ANTELO, T. y GABALDÓN, A. (2007). "Estudio radiográfico de la pieza” in OLCINA, M. (ed.) El báculo y la espada. Sobre un fragmento de escultura monumental romana de bronce de Lucentum, Alicante.

CHAMÓN, J., BARrio, J., ARrOYO, M., PARDO, A.I., ÁVILA A.L, GABALDÓN, A., ANTELO, T. y BUESO, M. (2007). "Inspección radiográfica de objetos dorados medievales de procedencia arqueológica", Boletín de la Asociación Española de Ensayos no Destructivos, no. 42, Madrid.

GABALDÓN, A., ANTElO, T., VEGA, C. y BUESO, M. (2008). "Un espacio para lo invisible”, Ciencia y Arte, Madrid.

TORRES, J., POSSE, A., MENÉNDEZ, J.M., GABALDÓN, A., VEGA, C., ANTELO, T., DEL EGIDO, M.A. y BUESO, M. (2008). "VARIM: A Useful System for Acquiring and Composing Images in Paintings Analysis Techniques”, (ISSN: 1646-9283), e_conservation. The online magazine, No. 4, April, pp. 27-42.

TORRES, J., POSSE, A., MENÉNDEZ, J.M., GABALDÓN, A., VEGA, C., ANTELO, T., DEL EGIDO, M. y BUESO, M. "VARIM: A Computer Vision System for the Automatic Creation of High Resolution Reflectographic Mosaics", at the ELMAR Congress. At press.

GABALDÓN, A., ANTELO, A. Y VEGA, C., (2010). "Estudio radiográfico del soporte de obras de dos autores castellanos del siglo XVI: Pedro Berruguete y Fernado Gallego", en La pintura europea sobre tabla, Madrid, Ministerio de Cultura, pp. 134-138.

GABALDÓN, A., ANTELO, A. Y VEGA, C., (2010). "Técnicas de imagen aplicadas al estudio de pinturas sobre tabla", en en La pintura europea sobre tabla, Madrid, Ministerio de Cultura, pp. 139-147.

GABALDÓN, A. y ANTELO, A. (2009). "Radiografía de gran formato", Patrimonio Cultural de España, Ministerio de Cultura, pp. 203-213.

ALBA, T., DALMAU, C., GABALDÓN, A., ANTELO, T. (2010). “Aplicación de la radiografía al estudio del retablo de Santoyo, atribuido a la Escuela de Juan de Flandes", Informes y Trabajos (revista digital), Ministerio de Cultura, pp. 11-18.

MARTÍN COSTEA, A., ANTELO, T., BUESO, M., GABALDÓN, A. (2010). "Estudio radiográfico de un conjunto de cabezas antropomorfas procedentes del complejo de Wunmonije, en Ife (Nigeria)", Informes y Trabajos (revista digital), Ministerio de Cultura, pp.85-95. 